\title{
The Impact Mechanisms of Psychological Learning Climate on Employees' Innovative Use of Information Systems
}

\begin{abstract}
Yuanyuan Guo, Collaborative Innovation Center for Transport Studies, School of Maritime Economics and Management, Dalian Maritime University, Dalian, China
\end{abstract}

Chaoyou Wang, School of Management Science and Engineering, Dongbei University of Finance and Economics, Dalian, China

\begin{abstract}
The aim of this study is to explore the impact mechanisms of psychological learning climate on employees' innovative use of information systems (IS). Using structural equation modeling, this study develops a theoretical model to investigate how the psychological learning climate affects innovative IS use by introducing individual motivational factors as mediators. The model is tested through a survey of 163 employees using enterprise resource planning (ERP) systems in China. The results suggest that psychological learning climate is positively related to innovative IS use both directly and indirectly. The indirect effect works through motivating employees' intrinsic motivation and creative self-efficiency. This study adds to the literature on IS use by identifying and examining the role of psychological learning climate as a driver of innovative IS use. The findings could provide managers with an understanding of how management can inspire employees' potential in IS innovation.
\end{abstract}

\section{KEYWORDS}

Creative Self-efficiency, Information Systems, Innovative Use, Intrinsic Motivation, Perceived Usefulness, Psychological Learning Climate

\section{INTRODUCTION}

Firms have made huge investments in information systems (IS), as they expect IS to bring great economic benefits. However, research suggests that over $60 \%$ of IS implementations result in continuous underutilization, thereby failing to meet expected investment returns (Veiga et al., 2013). The main reason for this is that, in most cases, employees operate at low levels of feature use and lack an innovative feature use (Wang et al., 2014; Li et al., 2013). To address the issue of underutilization, employees are expected to use IS in novel ways to perform new tasks or existing tasks in a different way, i.e., to conduct innovative IS use (Li et al., 2013).

The functional complexity of enterprise information systems, such as enterprise resource planning (ERP), supply chain management (SCM), business intelligence (BI), and other IS, provide users with the potential to apply IS at different levels of sophistication (Wang et al., 2008). Employee users can apply a complex IS in a simple and superficial way, sticking to work procedures and requirements as prescribed by managers; alternatively, they can user the complex IS at a higher level by utilizing the technology in creative ways that go beyond routine use ( $\mathrm{Li}$ et al., 2013). As technology and work become increasingly inseparable in modern organizations (Orlikowski and Scott, 2008), innovative

\section{DOI: 10.4018/JGIM.2020040103}

This article, originally published under IGI Global's copyright on December 20, 2019 will proceed with publication as an Open Access article starting on January 11, 2021 in the gold Open Access journal, Journal of Global Information Management (converted to gold Open Access January 1, 2021), and will be distributed under the terms of the Creative Commons Attribution License (http://creativecommons.org/ licenses/by/4.0/) which permits unrestricted use, distribution, and production in any medium, provided the author of the original work and 
IS use has critical implications because they help improve employee productivity, generate high value-adding products and services, and ultimately enhance organizations' competencies (BurtonJones and Straub Jr, 2006; Hsieh et al., 2011). Innovative IS use is such a high-level usage behavior that can extract the IS value potential to support employees' performance (Ahuja \& Thatcher, 2005). Toward this end, it is urgent to explore critical antecedents of employees' innovative IS use or the underlying mechanisms that drive the innovation process.

Although practitioners and scholars have realized that innovative IS use is important for realizing its potential benefits (Thatcher et al., 2011; Hsieh et al., 2011; Veiga et al., 2013), how to promote users' innovative IS use is still unknown. A few IS studies have suggested that individual characteristics are key determinants of innovative use, such as personality (Schmitz et al., 2016), absorptive capacity (Wang et al., 2014), and personal innovativeness (Li et al., 2013; Wang et al., 2013; Schmitz et al., 2016). Others have argued that motivational factors have tremendous impacts on users' innovative behaviors, such as intrinsic motivation (Li et al., 2013), self-efficiency (Wang et al., 2013; Peng et al., 2018), and perceived usefulness (Peng et al., 2018; Rezvani et al., 2017). Although academics have identified these motivational factors influencing innovative IS use, managers have had a difficult time identifying potential levers that raise users' motivation and thus promote their innovative IS use.

Although a few IS studies have contributed useful insights into the determinants of innovative IS use (Li et al., 2013; Wang et al., 2013), it is limited by the research focusing on individual factors. The attention paid to the influence of work environmental factors on IS innovation is limited. Recent studies have begun focusing on contextual factors, examining how team climate and psychological climate (user-perceived organizational environment) influence users' IS exploration behavior, which is a construct similar to IS innovation (Maruping \& Magni, 2012; Liang et al., 2015). Climate has been identified as a critical environmental factor influencing work-related innovation in organizational contexts and thus constitute a useful perspective for understanding how climate factors can affect users' innovation and exploration in the context of IS (Maruping \& Magni, 2012). Social influence theory suggests that individuals' immediate social environment is the most important information source that they employ to interpret and construct reality (Liang et al., 2010). Thus, this study argues that climate will inevitably influence users' IS usage behavior. Given that innovative use is innovative in nature, psychological learning climate is defined as individual employees' perceptions and evaluations of the work environment that values and emphasizes innovation, experimentation, and risk-taking (Edmondson, 1999; Carless, 2004; Maruping \& Magni, 2012), which is one of the most relevant environmental factors that can nurture and facilitate IS exploration and innovation (Worren et al., 2002; Scott \& Bruce, 1994; Liang et al., 2015). Yet, no attempt has been made to understand the impact mechanisms of psychological learning climate on IS innovation.

The objective of this study is to investigate how psychological learning climate influences innovative IS use through individual motivational factors. Drawing upon proactive motivation theory, this study develops a theoretical model to examine the impact mechanisms of psychological learning climate on innovative IS use. By pursuing the objective, our study contributes to the literature in two ways. First, this study contributes to the literature on IS use (Huang et al., 2017; Li et al., 2013; Ke et al., 2012; Wang et al., 2013; Schmitz et al., 2016; Peng et al., 2018) by identifying psychological learning climate as a critical antecedent of innovative use. This is important because until recently research on innovative use has primarily focused on individual factors (Li et al., 2013; Peng et al., 2018), but the attention paid to climate factors, especially facet-specific climates, has been limited. Second, this study adds to the limited research (Maruping \& Magni, 2012; Liang et al., 2015) that has responded to calls for more research examining the environmental factors on IS innovation by unpacking the impact mechanisms of psychological learning climate on innovative IS use. Although a few scholars have highlighted the importance of climate factors on IS innovation and exploration (Liang et al., 2015; Maruping \& Magni, 2012), the impact mechanisms of psychological climate on innovative use has not been answered. Our findings provide new insights into previous studies (Maruping \& Magni, 2012; Liang et al., 2015) by examining the mediating roles of intrinsic motivation and creative self-efficiency on the relationship between psychological learning climate and innovative IS use. 


\section{LITERATURE REVIEW}

\section{Theoretical Framework}

The framework of this study is building upon Parker et al.'s (2010) proactive motivation theory. Parker and her colleagues (Parker \& Collins, 2010; Griffin et al., 2007) have suggested that innovative performance results from proactive behaviors by which employees strive to bring about change to themselves and/or their environment. Furthermore, Parker et al. (2010) theorized that proactive motivational states (i.e., "can do motivation" and "reason to motivation") drive proactive behaviors, including innovativeness. Parker et al. (2010) proposed that proactive-oriented motivational states, including self-efficiency and intrinsic motivation, serve as proximal motivational mechanisms that facilitate employee innovation. Thus, the authors submit that employees' intrinsic motivation and self-efficiency retain their influence into the post-acceptance stages of complex IS innovations. Based on Parker et al.'s (2010) "can do motivation" and "reason to motivation" framework, the authors propose that perceived usefulness (extrinsic motivation) serving as another "reason to motivation" also influences IS innovation. Parker et al. (2010) suggested that situational variables (e.g., climate) could influence proactive motivational states, thereby boosting proactive goal processes, including innovativeness. Building upon this work, this study proposes that psychological learning climate positively associates with innovative IS use, with proactive motivational variables as mediators.

\section{Innovative Use and Its Antecedents}

The creativity research emphasized creativity/innovation as the production of novel and useful ideas by individuals or groups (Amabile et al., 1996). MacKinnon (1962) suggested that true creativity has three characteristics: (1) it involves a novel idea; (2) the idea must be useful; and (3) the creative idea can be put into action. In the meantime, the notion of Amabile (1988) that organizational innovation refers to the successful development and implementation of creative ideas is in line with McKinnon's view of creativity. Innovation can be illustrated in different forms, such as the outcome of recombining ideas or a proposal challenging current ways of doing things (Mills and Chin, 2007). As the thinking goes, innovative IS use embodies the generation and implementation of individual users' creative ideas in the form of IT usage behaviors. Specifically, innovative IS use can therefore be defined as a user's applying IS in novel ways to perform new tasks or existing tasks in a different way (Li et al., 2013), a high-level of usage behavior that surpasses routine or simple ways of use.

Innovative use describes a qualitatively post-acceptance IS usage behaviors performed by an employee to support his or her work, a high-level usage behavior that surpasses routine and simple ways of use (Li et al., 2013). Complex IS (e.g., ERP, BIS, SCM) are too sophisticated for organizations and users to fully appreciate and capitalize on its value during the initial acceptance stage (Hsieh \& Wang, 2007). When an IS implementation enters the post-acceptance stage, users' familiar with the installed system enables them to partake in innovative IS use that could not be identified at the initial acceptance stage (Jasperson et al., 2005). Innovative use differs from routine use in how the employee uses the system. Conceptually speaking, innovative IS use reflects the degree to which a person differs from others in the way he or she uses a particular information system in post-adoptive scenario.

In the IS field, there have been several similar concepts to explain users' creative application of IS. For example, some scholars focus on behavioral intentions or attempts, such as "trying to innovate with IT" (Ahuja \& Thatcher, 2005), IS exploration (Ke et al., 2012; Liang et al., 2015), and "intention to explore" (Maruping \& Magni, 2012). However, these concepts concern employees' attempt to innovate with IT and generate ideas (i.e., finding new ways of using IT), and not sure whether new ideas (i.e., new ways of using IS) are put into action. Emerging literature suggests that an intention or attempt to use an IT may not be the best predictor of usage behavior in the post-implementation context (Jasperson et al., 2005). Following this logic, this study focuses on users' behavior (i.e., innovative IS use) rather than behavior intentions or attempts. Innovative IS use focuses on post-implementation 
usage behavior that puts new ideas (i.e., new ways of using IS) into action. In the following section, the antecedents of innovative IS use in the literature are identified.

Researchers have identified many antecedents of IS innovation and exploration. For instance, some scholars investigate the influence of individual traits on IS innovation and exploration (Wang et al., 2014; Huang et al., 2017), such as absorptive ability, personality trait, personal innovativeness, and prior IT knowledge. Some individual motivational factors, such as intrinsic motivation, selfefficiency, and perceived usefulness, are found to increase IS exploration and innovation (Peng et al., 2018; Li et al., 2013; Wang et al., 2013). Compared with individual traits, individual motivations are more likely to be shaped by organizational levers. Thus, this study focuses on how to facilitate employees' motivations to use IS in novel ways in the IS post-implementation stage. Team climate and psychological climate (e.g., innovation climate, empowerment climate, and learning climate) are found to be able to facilitate employees' IS exploration, which is a construct similar to IS innovation (Maruping \& Magni, 2012; Liang et al., 2015). Although these studies have greatly improved our understanding of IS exploration and innovation, for the most part, they treat individual and environmental factors separately. Researches have suggested that climate factors have significant impacts on users' IS usage behavior by affecting their motivation and attitude (Xue et al., 2011), whereas the specific mediating mechanism between climates and IS innovation remains unexplored.

\section{Psychological Climate and Innovative Use}

Climate is considered a manifestation of organisational culture that can be conceptualised as either an organisational or psychological (individual-level) variable (Durcikova et al., 2011; Durcikova and Fadel, 2016). Carless (2004) suggested that psychological climate is an individual employee's perception and evaluation of their work environment, rather than the actual environment, and is directly linked to individual behavioral response. The concept of psychological climate is receiving increasing attention from IS researchers (Durcikova et al., 2011; Kettinger et al., 2015; Barkhi \& Kao, 2011; Wang et al., 2017); and is consistent with our focus on individual-level innovative behaviors. Thus, this study focuses on psychological climate at the individual level.

Although psychological climate has many facets (Koys \& DeCotiis, 1991), organizational scholars have recommended focusing on facet-specific climates that are expected to play a role in an environment in question (Anderson et al., 2014). Following this suggestion, this study focuses on psychological learning climate that is critical to innovative IS use. A learning climate exists when employees have the perceptions that experimentation, innovation and risk-taking, as well as collaboration, inquiry and discussion, are encouraged in the workplace (Edmondson, 1999; Maruping \& Magni, 2012).

Psychological learning climate can facilitate innovative behaviors such as IS innovation in multiple ways. First, a learning climate conveys about an organization's expectations and instrumentalities with regard to employees' innovative behavior (Scott \& Bruce, 1994; James et al., 1977; Yuan \& Woodman, 2010), which can direct employee users to regulate their behavior to be more innovative. Specifically, a learning climate conveys the social cues that innovative behavior is expected, supported, desired and rewarded by the organization, which provides motivation for employees to devote more effort to engaging in innovative behaviors (Bock et al., 2005; Anderson \& West, 1998). Second, a learning climate can foster innovative behavior by legitimating risk-taking (Yuan \& Woodman, 2010; West \& Wallace, 1991). Third, a learning climate encourages experimentation and risk-taking by offering psychological safety for taking risks without fear of negative consequences to status and career (Edmondson, 1999). Last but not least, a learning climate encourages employees to communicate and discuss novel ideas (Amabile et al., 1996). Long-term exposure to novel ideas can foster employees' learning and innovative thinking (Edmondson, 1999).

\section{Individual Motivational Factors and Innovative Use}

After conducting a literature review of recent literatures, the authors found that individual motivational factors are key antecedents of IS exploration and innovation (Ke et al., 2012; Li et al., 2013; Liu et al., 
2011). For instance, Li et al. (2013) suggested that intrinsic motivation has a stronger impact on IS innovation than perceived usefulness. Wang et al. (2008) proposed that computer self-efficiency and perceived usefulness are two important individual factors that facilitate innovation with information technology (IT). According to proactive motivational theory (Parker et al., 2010), there are two proactive-oriented motivational states, namely role-breadth self-efficiency and intrinsic motivation. Chen et al. (2013) further proposed that these two motivational states positively link between team climate and individual innovation. Based on proactive motivation theory, three proactive motivational factors that are critical for innovative IS use are selected in this study, namely intrinsic motivation, perceived usefulness, and creative self-efficiency.

Intrinsic motivation reflects the fact of doing an activity for its own sake: the activity itself is interesting, engaging, or in some way satisfying (Lee et al., 2005). Ryan and Deci (2000) contended that "intrinsic motivation could bring up high-quality learning and creativity." Perceived usefulness is considered as the most important extrinsic motivator toward information system (IS) use (Davis et al., 1992). According to Davis's (1989, p. 320), perceived usefulness is "the degree to which a person believes that using a particular system would enhance his or her job performance." Previous literature has identified the significant role of these two cognitive factors together in their research, for example, the effect on IS routine use and innovative use (Li et al., 2013), the level of IS assimilation (Liu et al., 2011), and exploratory usage of IS (Ke et al., 2012). Additionally, IS scholars have demonstrated a strong link between self-efficiency and individual reactions to IS usage behavior (Chen et al., 2013). Self-efficacy refers to beliefs in one's capabilities to organize and execute the courses of action required to produce desired results (Bandura, 1997). Because a few studies suggested that the effect of computer self-efficiency is non-significant on IS exploration (Wang et al., 2008; Schmitz et al., 2016), this study attempts to examine the impact of creative self-efficiency. Drawing from Bandura's definition, Tierney and Farmer (2002) defined the concept of creative self-efficiency as "the belief one has the ability to produce creative outcomes." This study extends Tierney and Farmer's (2002) definition to IS context and defines creative self-efficiency as "users' belief about their ability to use IS innovatively".

Notably, our attention is not to examine an exhaustive list of factors but rather to focus on the three proactive motivational factors that are critical for innovative IS use. As a consequence, this study furthers our understanding of how these three motivational factors mediate the relationship between psychological learning climate and innovative IS use.

\section{The Missing Link in the Literature}

The extant literatures suggest that climate factors have positive impacts on IS innovation and exploration (Maruping \& Magni, 2012; Liang et al., 2015). Individual motivational factors, such as intrinsic motivation, perceived usefulness, and self-efficiency are positively associated with IS innovation and exploration (Wang et al., 2013; Li et al., 2013). Although these studies have greatly improved our understanding of IS exploration and innovation, for the most part, they treat individual and environmental factors separately. Researches have suggested that climates have significant impacts on users' IS usage behavior by affecting their motivation and cognition (Xue et al., 2011), whereas the specific mediating mechanism between climates and IS innovation remains unexplored.

Although academics and practitioners have realized the significance of innovative IS use in the post-implementation stage ( $\mathrm{Li}$ et al., 2013), how to make users develop innovative use is a key challenge for management. Prior literatures suggest that employees' motivations and cognitions are positively associated with their innovative behavior (Wang et al., 2008; Schmitz et al., 2016; Wang et al., 2013). An organization needs to facilitate employees' intrinsic motivation, perceived usefulness, and self-efficiency to strengthen innovative IS use. One key question is, what should management do to foster users' motivations and cognitions to use IS in novel ways in the post-implementation stage? This critical issue is yet to be addressed in the IS research literature. 


\section{RESEARCH MODEL AND HYPOTHESES}

This study proposes seven hypotheses grounded in the context of IS innovation. The proposed research model is shown in Figure 1.

\section{The Role of Psychological Learning Climate}

Organizational researchers have consistently shown that a climate emphasizing innovation can stimulate innovation in the workplace (Scott \& Bruce, 1994; Anderson \& West, 1998). With this logic, this study proposes that a learning climate is likely to influence IS users' innovative behavior. Prior research provides strong support for this hypothesis. First, a learning climate signals to employees that pursuing innovative and novel ways of accomplishing tasks via IS innovation is encouraged (Anderson \& West, 1998; Koys \& DeCotiis, 1991; Amabile et al., 1996). A learning climate emphasizing innovation has been found to be positively related to IS exploration, which is a construct similar to IS innovation (Maruping \& Magni, 2012, 2015; Liang et al., 2015). Second, a learning climate assures employees that their experimental behavior and risk-taking with IS innovation will be encouraged and even if they fail there will be no negative consequences (Edmondson, 1999). With reduced fear of failure, employees are more willing to engage in IS innovation. Finally, a learning climate encourages employees to communicate and voice novel ideas regarding IS use (Xue et al., 2011; Bock et al., 2005). Continuous exposure to diverse novel ideas can facilitate employees' learning, including their understanding of systems features and business processes, and they are consequently better prepared to innovate with IS usage (Liang et al., 2015). Therefore, the authors expect that IS users with a high perceived learning climate will be more likely to apply IS in novel and innovative ways. This leads to the following hypothesis:

H1: Psychological learning climate is positively related to innovative IS use.

Psychological learning climate exists when employees have the perceptions that experimentation, innovation, and risk-taking, as well as collaboration, inquiry, and discussion are encouraged in the workplace (Maruping \& Magni, 2012). Amabile et al. (1996) stated that employees' psychological perceptions of innovation climate may influence their motivation to bring up new ideas. In the context

Figure 1. Proposed research model

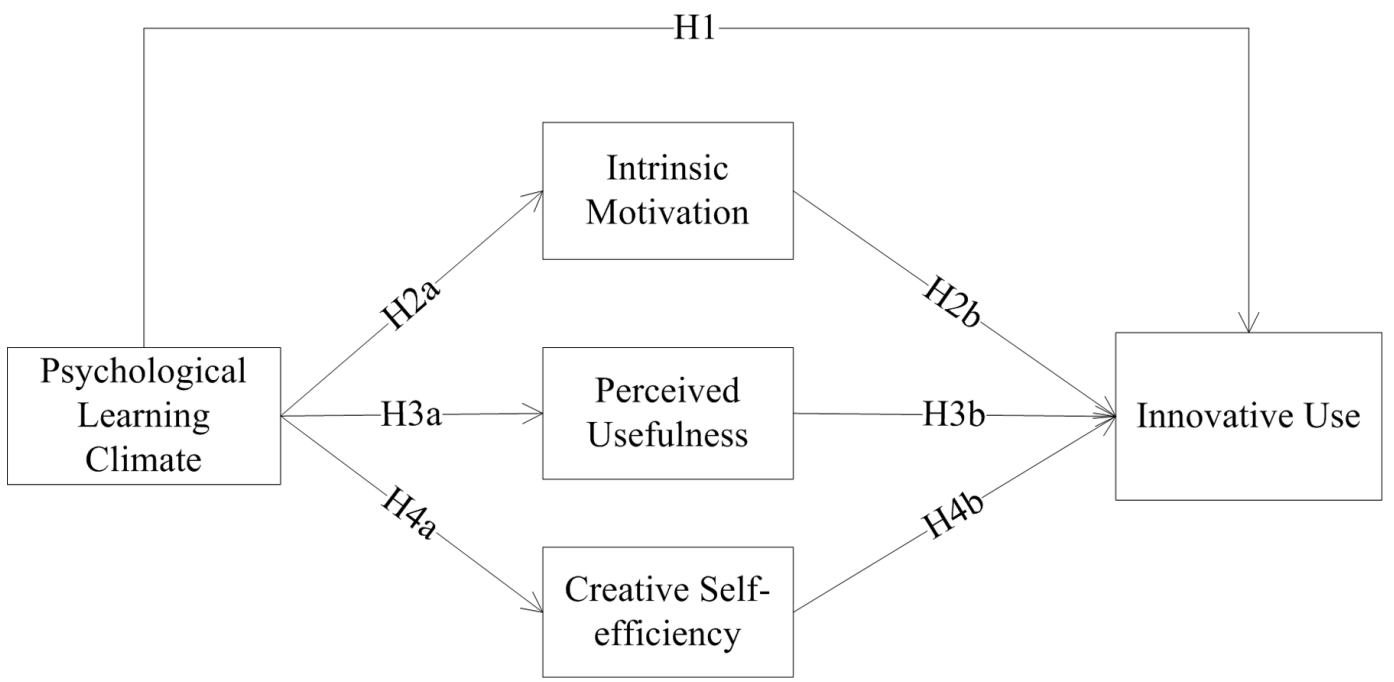


of IS innovation, psychological learning climate are supportive of innovation behavior which signifies that innovative activities and behaviors are valuable and meaningful within the organization, therefore, enhancing users' intrinsic motivation to innovate with IS applications. Additionally, employees in a learning climate have the perceptions that other members will not embarrass, reject, or punish someone for speaking up (Edmondson, 1999; Maruping \& Magni, 2012). Consequently, individuals will have higher levels of psychological safety and motivation to apply IS innovatively. Thus, the following hypothesis is proposed:

H2a: A user's psychological learning climate is positively related to his/her intrinsic motivation.

In the context of IS innovation, a learning climate reflects an organization's expectation, approval, and practical support of attempts to introduce novel and improved ways of using IS (Liang et al., 2015), providing clues about the plausible consequences of using IS (Wang et al., 2008). Thus, members will aware of the IS usefulness, when they perceive that innovative use is encouraged at work. The innovation-friendly environment can increase salience of IS usefulness by calling attention to certain aspects of the systems. Additionally, if employees perceive that innovation is supported, an individual is more likely to discover new ways to perform his job using IS applications, which in turn enhances positive perceptions of IS use (perceived usefulness). Thus, the following hypothesis is proposed:

H3a: A user's psychological learning climate is positively related to his/her perceived usefulness of IS applications.

A psychological learning climate means that employees will receive spiritual and material support need to innovate successfully when they are engaging in innovative activities and behaviors (Liang et al., 2015). Thus, this study argues that a learning climate can enhance employees' confidence for performing IS innovation effectively (i.e., creative self-efficiency). Additionally, a learning climate favors inquiry, collaboration, and discussion, and thus employees collaborate and help each other at work, which will enhance their creative self-efficiency to conduct innovative IS use. Thus, the following hypothesis is proposed:

H4a: A user's psychological learning climate is positively related to his/her creative self-efficiency.

\section{The Role of Individual Motivational Factors}

\section{The Role of Intrinsic Motivation}

According to creativity theory, innovative, complex, and extra-role tasks, such as innovative IS use, require users to be intrinsically motivated (Deci \& Ryan, 2000). In the context of IS innovation, if a user considers IS use as enjoyable and interesting, he or she is more likely to devote their time and efforts to exploring IS functions and using IS in novel ways. Thus, employees who have higher intrinsic motivations may display much higher determination, concentration, and flexibility but may feel less pressured when pursuing innovative IS use (Li et al., 2013; Vallerand, 1997). Thus, the following hypothesis is proposed:

H2b: A user's intrinsic motivation is positively related to the level of his/her innovative IS use.

\section{The Role of Perceived Usefulness}

Perceived usefulness refers to employees' perceptions that using IS can lead to better performance (Davis, 1989). PU is considered as a representative surrogate construct of extrinsic motivation toward IS use, because better performance ultimately contributes to gaining material rewards such 
as payment and promotion (Davis et al., 1992). When employees perceive that innovative IS use would result in instrumental benefits, they may engage in innovative use to support their tasks (Li et al., 2013). With this logic, if a user conceives IS innovative use as being useful for improving their work performance, they are likely to devote time and effort engaging in innovative use. Thus, the following hypothesis is proposed:

H3b: A user's perceived usefulness of IS applications is positively related to the level of his/her innovative IS use.

\section{The Role of Creative Self-Efficiency}

Creative self-efficiency refers to users' belief about their ability to use IS innovatively. Self-efficiency has been identified as a critical antecedent for individuals' efforts on and persistence in attempting some specific behaviors (Igbaria \& Iivari, 1995). Parker and her colleagues (Parker, 2000; Parker et al., 2010; Parker \& Collins, 2010) have indicated that individuals with higher self-efficiency are more confident in their ability to generate and implement new ideas and, therefore, motivates their engagement in innovative behaviors. With this logic, IS users who are highly confident of their efficiency are more likely to adhere to exploring IS features by bringing up new and useful ideas and make more efforts to apply IS in innovative ways. Therefore, despite accompanying potential risks, employees with a high creative self-efficiency are likely to persevere with innovative IS use (Peng et al., 2018). Thus, the following hypothesis is proposed:

H4b: A user's creative self-efficiency is positively related to the level of his/her innovative IS use.

\section{RESEARCH METHODOLOGY}

\section{Survey Development}

In this study, all the measurement items are based on a 7-point Likert scale. The items for each construct are adapted from existing scales in the proposed model. The questionnaire was translated carefully into Chinese, since most literature is written in English. A panel of experts was invited to examine the face validity of the items. The measurement of creative self-efficiency needs a detail explanation. Since there are no established measures available for creative self-efficiency in the IS literature, a few changes are made to the scales so as to match the IS innovation contexts. The Appendix A provides the full questionnaire items and the sources of them.

\section{Data Collection}

This study uses a survey to examine the proposed hypotheses. This study chooses enterprise information systems (ERP) as the target system to test the hypotheses, since ERP systems are typical complex IS (Wang \& Hsieh et al., 2008). A structured questionnaire is used for data collection in this study. To find appropriate respondents, the authors contacted a large ERP software provider in Harbin, China. To achieve sufficient variance in our model constructs, the authors carefully selected the firms to increase the diversity of industry types, ownership types, and the amount of time since their IS implementation. The authors sought companies that had successfully implemented an ERP system at least 18 months prior to our data collection-well beyond the typical 8-12-month acceptance timeframe for major IS implementation initiatives (Rezvani et al., 2017; Morris \& Venkatesh, 2010; $\mathrm{Li}$ et al., 2013). After the selection process, invitations were sent to the companies we selected. Ten companies agreed to participate in our study. The ten companies are in six industries, have three different ownership types, and have implemented ERP for an average of 4.8 years (see Table 1). 
The questionnaires are administrated to 200 subjects from the ten selected companies using stratified sampling approach. Innovative IS use is suggested to occur during the post-implementation stage when users have passed their initial use decisions and become more knowledgeable about the implemented IS (Wang et al., 2013; Peng et al., 2018). Users' familiar with the IS serves as their knowledge base, which helps them to go beyond the status quo and identify new ways of applying IS (Wang et al., 2013). Thus, the respondents should have at least half a year system usage experience. This would be ample time for users to achieve a reasonably high level of proficiency with its key applications (Veiga et al., 2013) and further have the ability to innovate with IS usage. To satisfy ample time for users to familiar with installed IS, the employees from finance department are preferred in the data collection process. The reason is that the predecessor of ERP software in China was accounting and financial software, most firms firstly implement IS in the finance department, and thus employees in the finance department have more IS usage experience and are more likely to use IS in novel ways. Therefore, a significant number of respondents were financial users. Of the 200 questionnaires distributed, 178 questionnaires are returned. To increase the number of responses, incentives were offered to each respondent. The authors deleted the questionnaires in which the respondent's system experience is lower than six months or the questionnaires with incomplete or missing data. Finally, 163 questionnaires are qualified and taken into consideration in the analysis. Suggested by $\mathrm{Ke}$ et al. (2012) for examining a non-response bias, this study compares the chi-squares of the responses to demographic questions from the first 25 percent to the final 25 percent of the respondents. The results show that there are no significant differences $(\mathrm{p}>0.05)$ between the two groups, indicating the presence of a non-response bias. The demographics of the respondents are shown in Table 2.

\section{DATA ANALYSIS AND RESULTS}

This study applies SmartPLS 3.0 to analyze the measurement quality and the path model. First, the authors assess the measurement scales by examining convergent validity, discriminant validity, and internal consistency reliability. Then, the authors analyze the structural model to test the proposed hypotheses and the overall quality of the structural model.

\section{Common Method Bias and Multicollinearity Test}

As with all self-reported data, two methods were used to examine common method bias (CMB) in this study. First, we conducted a Harman's single factor test to examine common method bias (Zhou et al., 2012; Podsakoff et al., 2003). In Harman's single factor test, three factors with eigenvalues greater than one were generated with no single factor accounting for the majority of the variance in the items (Podsakoff et al., 2003). Second, based on Liang et al.'s (2007) study, the authors added a common method factor whose indicators included all the principal constructs' indicators in the structural model. The authors calculated each indicator's variances substantively explained by the principal construct. The analysis results are shown in Table $3\left(\mathrm{R}_{1}^{2}\right.$ represents indicators' variances explained by the principle construct; $\mathrm{R}_{2}^{2}$ represents indicators' variances explained by the method construct). As shown in Table 3, the results indicate that all of the substantive factor loadings are significant, while all of the method factor loadings are insignificant. The average substantively explained variance of the indicators is 0.813 , while the average method-based variance is 0.013 . The ratio of substantive variance to method variance is about $63: 1$. The evidence collectively suggests that $\mathrm{CMB}$ is not a serious validity threat.

In addition, this study conducted a multicollinearity test by assessing the variance inflation factors (VIFs) of the constructs. One item for perceived usefulness was removed for excessive multicollinearity with variance inflation factors greater than 5 (Schmitz et al., 2016). After removing this item, the results indicate that the VIFs for all the constructs were smaller than the threshold of 3.33 (Diamantopoulos and Siguaw, 2006; Zhou et al., 2012; Peng et al., 2018), indicating no harmful multicollinearity. As such, multicollinearity did not appear to be a significant problem with our research. 
Table 1. Basic information of responding firms

\begin{tabular}{|l|l|l|l|l|}
\hline \multicolumn{1}{|c|}{ Company } & \multicolumn{1}{|c|}{ Industry type } & \multicolumn{1}{|c|}{ Ownership } & \multicolumn{1}{c|}{$\begin{array}{c}\text { Time since ERP } \\
\text { implementation } \\
\text { (years) }\end{array}$} & \multicolumn{1}{c|}{$\begin{array}{c}\text { Number of } \\
\text { respondents }\end{array}$} \\
\hline A & Manufacturing & Joint venture & 6 & 63 \\
\hline B & $\begin{array}{l}\text { Retailing and } \\
\text { wholesale }\end{array}$ & Privately-owned & 8 & 17 \\
\hline C & Hospitals & State-owned & 3 & 9 \\
\hline D & Hospitals & State-owned & 3 & 9 \\
\hline E & Tourism and leisure & Privately-owned & 6 & 10 \\
\hline F & Manufacturing & Joint venture & 7 & 11 \\
\hline G & Tourism and leisure & Privately-owned & 5 & 10 \\
\hline H & Hospitals & State-owned & 4 & 11 \\
\hline I & $\begin{array}{l}\text { Broadcast and } \\
\text { television }\end{array}$ & State-owned & 2 & 14 \\
\hline J & $\begin{array}{l}\text { Retailing and } \\
\text { wholesale }\end{array}$ & Privately-owned & 4 & 9 \\
\hline
\end{tabular}

\section{Quality of Measurement Model}

Convergent validity refers to the degree to which the measurement scales are related to the corresponding construct by checking the average variance extracted (AVE) of each construct from its indicators. As shown in Table 4, all the AVE scores are greater than 0.7, which are above the recommended value of 0.5. In addition, Hulland (1999) indicates that item loadings below 0.5 should be discarded. All items loadings are greater than the recommended minimum value of 0.5 . Hence, the results indicate that the measurement items have good convergent validity.

There are two main methods for assessing discriminant validity (Straub et al., 2004). The first method is comparing the square root of the AVE of each construct and this construct's correlation with other constructs. As presented in Table 5, the diagonal values are the square root of AVE for each construct, which is greater than the correlations with all other constructs, indicating good discriminant validity. The second method is comparing the item loadings of on their own construct and the cross-loadings on any other construct. Table 6 shows the cross loadings of the items on all constructs, which also indicates reasonable discriminant validity.

The reliability of the measurement scales is regarded as acceptable when each construct's composite reliability, Cronbach's alpha score has exceeded 0.7 (Chin et al., 2003). Table 4 shows that the lowest composite reliability is 0.883 and the lowest Cronbach's alpha is 0.839 (Gefen et al., 2000), indicating acceptable internal consistency reliability.

\section{Structural Path Analysis}

Path analysis results are showed in Figure 2. Overall, our results show support for the proposed research model and yield several interesting observations. Among the hypotheses, only the impact of perceived usefulness on innovative use is insignificant, indicating that perceived usefulness is not the mediator between psychological learning climate and innovative use. The rest hypotheses are supported at $\mathrm{p}<0.1$ level. The insignificance of the relationships between perceived usefulness and innovative use is intriguing but not surprising. One reason may be that although perceived usefulness has been considered as one important determinant for IS usage, however, its focal behaviors are on routine usage ( $\mathrm{Li}$ et al., 2013). As indicated by Li et al. (2013), perceived usefulness has a stronger 
Table 2. Respondent profiles

\begin{tabular}{|c|c|c|c|}
\hline Category & Subcategory & Count & Percentage (\%) \\
\hline \multirow{2}{*}{ Gender } & Male & 59 & 36.2 \\
\hline & Female & 104 & 63.8 \\
\hline \multirow{3}{*}{ Age } & $<30$ years old & 60 & 36.8 \\
\hline & $30-50$ years old & 93 & 57.1 \\
\hline & $>50$ years old & 10 & 6.1 \\
\hline \multirow{4}{*}{ Education } & High school & 6 & 3.7 \\
\hline & Junior college & 67 & 41.1 \\
\hline & Undergraduate & 84 & 51.5 \\
\hline & Graduate & 6 & 3.7 \\
\hline \multirow{6}{*}{ Working department } & Purchasing & 25 & 15.3 \\
\hline & Sales & 26 & 16.0 \\
\hline & Production & 17 & 10.4 \\
\hline & Finance & 64 & 39.3 \\
\hline & Inventory & 11 & 6.7 \\
\hline & Others & 20 & 12.3 \\
\hline \multirow{4}{*}{ Job title } & Senior managers & 0 & 0 \\
\hline & Division managers & 7 & 4.3 \\
\hline & Team leader & 19 & 11.7 \\
\hline & Employee & 137 & 84.0 \\
\hline \multirow{3}{*}{ System experience } & $<5$ years & 66 & 40.5 \\
\hline & $5-10$ years & 48 & 29.4 \\
\hline & $>10$ years & 49 & 30.1 \\
\hline \multirow{3}{*}{ Work experience } & $<5$ years & 50 & 30.7 \\
\hline & 5-10 years & 18 & 11.0 \\
\hline & $>10$ years & 95 & 58.3 \\
\hline
\end{tabular}

impact effect on routine use than intrinsic motivation, but it is less influential for innovative use. The direct link between psychological learning climate and innovative use is significant, which provides support for Hypothesis 1 (regression coefficient $\beta=0.205$ ). The path coefficients between psychological learning climate and individual motivational factors, namely intrinsic motivation, perceived usefulness, and creative self-efficiency, are all significant at $\mathrm{p}<0.01$ level, providing support for hypotheses $\mathrm{H} 2 \mathrm{a}, \mathrm{H} 3 \mathrm{a}$, and $\mathrm{H} 4 \mathrm{a}$. In addition, path analysis suggests that intrinsic motivation and creative self-efficiency are positively related to innovative IS use. Specifically, the path coefficient between intrinsic motivation and innovative usage is 0.137 and is significant at $\mathrm{p}<0.1$ level $(\mathrm{H} 2 \mathrm{~b})$, indicating that intrinsic motivation has a moderate impact on innovative use. In comparison, the impact of creative self-efficiency is strong, with regression coefficient $\beta=0.401$, and is significant at $\mathrm{p}<0.01$ level (H4b).

The overall quality of the structural model is indicated by the adjusted $\mathrm{R}^{2}$ values of the endogenous variables (Hulland, 1999). The adjusted $\mathrm{R}^{2}$ value for the dependent variable of innovative use is 0.475 , indicating a strong explanatory power of the model. All the control variables have non-significant 
Table 3. Common method bias results

\begin{tabular}{|c|c|c|c|c|}
\hline Indicator & $\begin{array}{c}\text { Substantive factor } \\
\text { loading }\left(\mathbf{R}_{\mathbf{1}}\right)\end{array}$ & $\mathbf{R}_{1}^{2}$ & $\begin{array}{c}\text { Method factor } \\
\text { loading }\left(\mathbf{R}_{2}\right)\end{array}$ & $\mathbf{R}_{2}^{2}$ \\
\hline PLC1 & $0.971 * *$ & 0.943 & $0.034 \mathrm{~ns}$ & 0.0012 \\
\hline PLC2 & $0.852 * *$ & 0.726 & $0.007 \mathrm{~ns}$ & 0.0001 \\
\hline PLC3 & $0.949 * *$ & 0.901 & $-0.042 \mathrm{~ns}$ & 0.0018 \\
\hline IM1 & $0.855^{* *}$ & 0.731 & $-0.084 \mathrm{~ns}$ & 0.0071 \\
\hline IM2 & $0.780 * *$ & 0.608 & $0.188 \mathrm{~ns}$ & 0.0353 \\
\hline IM3 & $0.902 * *$ & 0.814 & $-0.104 \mathrm{~ns}$ & 0.0108 \\
\hline PE1 & $0.986^{* *}$ & 0.972 & $-0.106 \mathrm{~ns}$ & 0.0112 \\
\hline PE2 & $0.914 * *$ & 0.835 & $0.103 \mathrm{~ns}$ & 0.0106 \\
\hline CSE1 & $0.872 * *$ & 0.760 & $0.074 \mathrm{~ns}$ & 0.0055 \\
\hline CSE2 & $0.973^{* *}$ & 0.945 & $-0.081 \mathrm{~ns}$ & 0.0066 \\
\hline CSE3 & $0.922 * *$ & 0.850 & $0.007 \mathrm{~ns}$ & 0.0000 \\
\hline INNU1 & $0.963 * *$ & 0.927 & $-0.034 \mathrm{~ns}$ & 0.0012 \\
\hline INNU2 & $0.973 * *$ & 0.947 & $-0.196 \mathrm{~ns}$ & 0.0384 \\
\hline I NNU3 & $0.653 * *$ & 0.426 & $0.227 \mathrm{~ns}$ & 0.0515 \\
\hline
\end{tabular}

Notes: ${ }^{*} p<.05 ;{ }^{* *} p<.01$

Table 4. Measurement quality indicators

\begin{tabular}{|c|c|c|c|c|c|}
\hline Latent construct & Items & Loadings & $\begin{array}{l}\text { Composite } \\
\text { Reliability }\end{array}$ & $\begin{array}{c}\text { Cronbachs } \\
\text { Alpha }\end{array}$ & AVE \\
\hline \multirow{3}{*}{$\begin{array}{l}\text { Psychological } \\
\text { learning Climate } \\
\text { (PLC) }\end{array}$} & PLC1 & 0.871 & \multirow{3}{*}{0.883} & \multirow{3}{*}{0.875} & \multirow{3}{*}{0.873} \\
\hline & PLC2 & 0.874 & & & \\
\hline & PLC3 & 0.782 & & & \\
\hline \multirow{3}{*}{$\begin{array}{l}\text { Intrinsic } \\
\text { Motivation (IM) }\end{array}$} & IM1 & 0.938 & \multirow{3}{*}{0.966} & \multirow{3}{*}{0.947} & \multirow{3}{*}{0.904} \\
\hline & IM2 & 0.947 & & & \\
\hline & IM3 & 0.966 & & & \\
\hline \multirow{2}{*}{$\begin{array}{l}\text { Perceived } \\
\text { Usefulness (PU) }\end{array}$} & PE1 & 0.991 & \multirow{2}{*}{0.992} & \multirow{2}{*}{0.985} & \multirow{2}{*}{0.985} \\
\hline & PE2 & 0.994 & & & \\
\hline \multirow{3}{*}{$\begin{array}{l}\text { Creative Self- } \\
\text { efficiency (CSE) }\end{array}$} & CSE1 & 0.987 & \multirow{3}{*}{0.991} & \multirow{3}{*}{0.986} & \multirow{3}{*}{0.973} \\
\hline & CSE 2 & 0.993 & & & \\
\hline & CSE 3 & 0.978 & & & \\
\hline \multirow{3}{*}{$\begin{array}{l}\text { Innovative Use } \\
\text { (INNU) }\end{array}$} & INNU1 & 0.934 & \multirow{3}{*}{0.902} & \multirow{3}{*}{0.839} & \multirow{3}{*}{0.756} \\
\hline & INNU2 & 0.826 & & & \\
\hline & INNU3 & 0.844 & & & \\
\hline
\end{tabular}


Table 5. Correlations between each two constructs

\begin{tabular}{|l|l|l|l|l|l|}
\hline \multicolumn{1}{|c|}{ Latent construct } & \multicolumn{1}{|c|}{ PLC } & \multicolumn{1}{c|}{ IM } & \multicolumn{1}{c|}{ PU } & \multicolumn{1}{c|}{ CSE } & INNU \\
\hline Psychological Learning Climate (PLC) & $\mathbf{0 . 9 3 4}$ & & & & \\
\hline Intrinsic Motivation (IM) & 0.518 & $\mathbf{0 . 9 5 1}$ & & & \\
\hline Perceived Usefulness (PU) & 0.462 & 0.686 & $\mathbf{0 . 9 9 2}$ & & \\
\hline Creative Self-efficiency (CSE) & 0.460 & 0.659 & 0.615 & $\mathbf{0 . 9 8 6}$ & \\
\hline Innovative Use (INNU) & 0.532 & 0.549 & 0.296 & 0.641 & $\mathbf{0 . 8 6 9}$ \\
\hline
\end{tabular}

Table 6. Cross loadings of the constructs

\begin{tabular}{|c|c|c|c|c|c|}
\hline Item & $\begin{array}{l}\text { Psychological } \\
\text { Learning } \\
\text { Climate } \\
\text { (PLC) }\end{array}$ & $\begin{array}{c}\text { Intrinsic } \\
\text { Motivation (IM) }\end{array}$ & $\begin{array}{c}\text { Perceived } \\
\text { Usefulness (PU) }\end{array}$ & $\begin{array}{l}\text { Creative Self- } \\
\text { efficiency (CSE) }\end{array}$ & $\begin{array}{c}\text { Innovative Use } \\
\text { (INNU) }\end{array}$ \\
\hline PLC1 & 0.871 & 0.486 & 0.442 & 0.505 & 0.532 \\
\hline PLC2 & 0.874 & 0.541 & 0.476 & 0.402 & 0.528 \\
\hline PLC3 & 0.782 & 0.488 & 0.433 & 0.439 & 0.495 \\
\hline IM1 & 0.493 & 0.939 & 0.702 & 0.592 & 0.468 \\
\hline IM2 & 0.512 & 0.947 & 0.699 & 0.732 & 0.567 \\
\hline IM3 & 0.471 & 0.966 & 0.613 & 0.663 & 0.524 \\
\hline PE1 & 0.422 & 0.656 & 0.991 & 0.561 & 0.334 \\
\hline PE2 & 0.488 & 0.719 & 0.994 & 0.651 & 0.425 \\
\hline CSE1 & 0.493 & 0.675 & 0.631 & 0.987 & 0.644 \\
\hline CSE2 & 0.440 & 0.632 & 0.585 & 0.993 & 0.626 \\
\hline CSE3 & 0.427 & 0.703 & 0.601 & 0.979 & 0.626 \\
\hline INNU1 & 0.382 & 0.493 & 0.369 & 0.648 & 0.934 \\
\hline INNU2 & 0.396 & 0.367 & 0.250 & 0.448 & 0.826 \\
\hline I NNU3 & 0.600 & 0.548 & 0.369 & 0.550 & 0.844 \\
\hline
\end{tabular}

effect, which is consistent with the results of Li et al. (2013) and Wang et al. (2014). The model without control variables explains 45.8 percent of the variance in innovative IS use while with control variables explains 47.5 percent.

\section{Mediation Analysis}

This study follows the procedure suggested by Baron and Kenny (1986) to test the mediating role of intrinsic motivation and creative self-efficiency. Then, this study analyzes the relative size of the mediating effect (full or partial mediation) based on the literatures Sobel (1982) and Preacher and Hayes (2004). According to Baron and Kenny (1986), in a three variable causal model $(X \rightarrow M \rightarrow Y)$, the mediation hypothesis that $\mathrm{M}$ mediates the effect of $\mathrm{X}$ on $\mathrm{Y}$ is supported if the following conditions hold in different individual regression models: in Model 1, the independent variable $\mathrm{X}$ is associated with the mediator M significantly; in Model 2, the independent variable $\mathrm{X}$ is associated with the dependent variable Y significantly without the mediator M; and in Model 3 with both the independent variable $\mathrm{X}$ and the mediator $\mathrm{M}$ predicting the outcome, the mediator $\mathrm{M}$ is associated with the dependent 


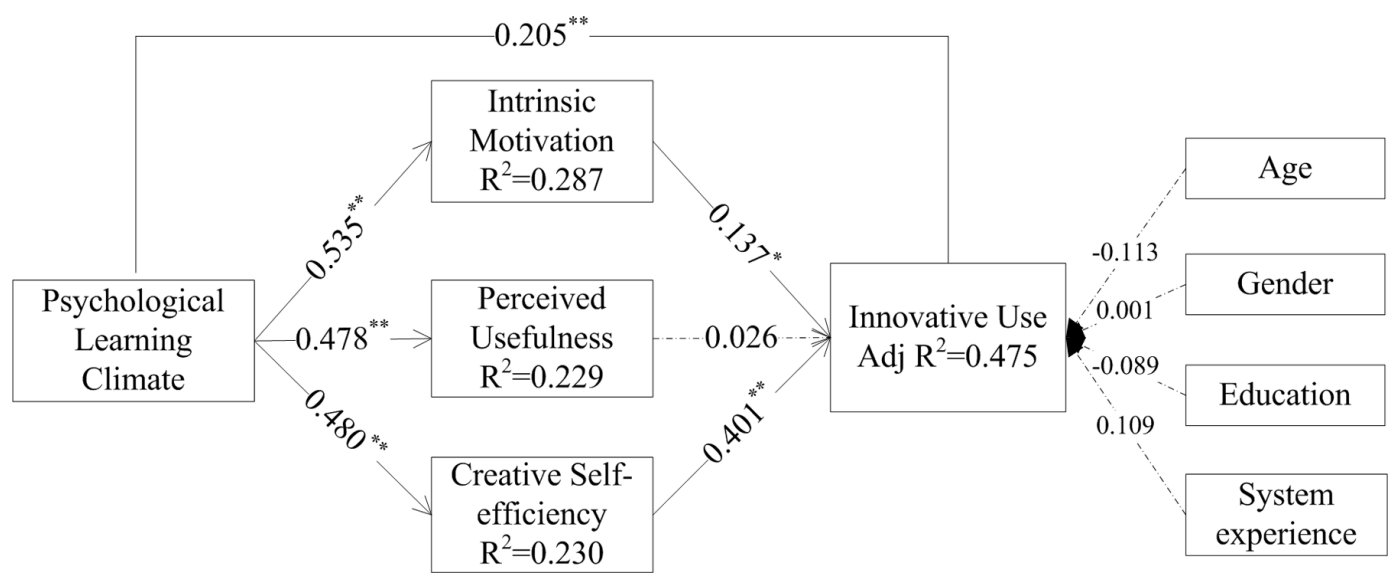

variable $\mathrm{Y}$ significantly, and the effect of independent variable $\mathrm{X}$ on the dependent variable $\mathrm{Y}$ is reduced to zero (full mediation) or reduced by a significant amount (partial mediation). Similar to Hu et al. (2012), this study tests three individual regression models, and show the regression results based on Baron and Kenny (1986) procedure (in Table 7). The results show that the mediation role of intrinsic motivation and creative self-efficiency are confirmed.

To further test the mediation effect, this study performed the Sobel test, which provides a direct test of the indirect effect of an independent variable on the dependent variable through the mediator (Preacher \& Hayes, 2004; Sobel, 1982). To perform the test, this study employed the bootstrapping approach, thereby making no assumption about the distribution of individual effect and providing confidence intervals for the estimate (Preacher \& Hayes, 2004). In Table 8, the value of variance accounted for (VAF) indicates the relative size of mediating effect of intrinsic motivation and creative self-efficiency. According to Sobel (1982), the path from independent variable to the mediator is denoted as $a$; the path from the mediator to the dependent variable is denoted as $b$. The indirect effect was calculated based on $\alpha$ Path Coefficient and $b$ Path Coefficient, and confirm the significance for the indirect effect (Sobel, 1982). The VAF value suggests that intrinsic motivation and creative selfefficiency both partially mediated the effect of psychological learning climate on innovative IS use.

Table 7. Testing mediating effect of intrinsic motivation, creative self-efficiency on the relationship between psychological learning climate and innovative IS use

\begin{tabular}{|c|c|c|c|c|c|c|c|c|c|c|}
\hline \multirow{2}{*}{$\begin{array}{c}\text { Ind. } \\
\text { variables }\end{array}$} & \multicolumn{2}{|c|}{ Base model } & \multicolumn{2}{|c|}{ Model 1a: PLC $\rightarrow$ IM } & \multicolumn{2}{|c|}{ Model 1b: PLC $\rightarrow$ CSE } & \multicolumn{2}{|c|}{$\begin{array}{l}\text { Model 2: } \\
\text { PLC } \rightarrow \text { INNU }\end{array}$} & \multicolumn{2}{|c|}{$\begin{array}{c}\text { Model 3: PSL, CSE, } \\
\text { IM } \rightarrow \text { INNU }\end{array}$} \\
\hline & $B$ & $t$ & B & $t$ & $B$ & $t$ & B & $t$ & $B$ & $t$ \\
\hline AGE & -0.290 & 1.031 & & & & & -0.250 & 1.219 & -0.139 & 0.733 \\
\hline GEN & 0.140 & 0.635 & & & & & 0.144 & 1.035 & 0.053 & 0.343 \\
\hline EDU & 0.098 & 0.743 & & & & & -0.025 & 0.244 & -0.127 & 1.437 \\
\hline SEXP & 0.487 & $2.071^{* *}$ & & & & & 0.254 & 1.261 & 0.124 & 0.652 \\
\hline IM & & & 0.537 & $4.906^{* * *}$ & & & & & 0.131 & $1.702 *$ \\
\hline CSE & & & & & 0.484 & $4.020 * * *$ & & & 0.401 & $3.372 * * *$ \\
\hline PLC & & & & & & & 0.542 & $4.254 * * *$ & 0.207 & $2.761 * *$ \\
\hline Adj. $R^{2}$ & \multicolumn{2}{|l|}{0.036} & \multicolumn{2}{|l|}{0.271} & \multicolumn{2}{|l|}{0.215} & \multicolumn{2}{|l|}{0.289} & \multicolumn{2}{|l|}{0.443} \\
\hline
\end{tabular}

Notes: Significant at ${ }^{*} p<0.1,{ }^{* *} p<0.05 ;{ }^{* \star *} p<0.001$ 
Table 8. Mediation analysis results

\begin{tabular}{|c|c|c|c|c|c|c|c|c|c|c|c|c|}
\hline & \multicolumn{2}{|c|}{$\begin{array}{l}\text { Direct effect } \\
\text { without } \\
\text { mediation }\end{array}$} & \multicolumn{2}{|c|}{$\begin{array}{c}\text { Direct effect } \\
\text { with mediation }\end{array}$} & \multicolumn{2}{|c|}{$\begin{array}{l}\text { a Path } \\
\text { coefficient }\end{array}$} & \multicolumn{2}{|c|}{$\begin{array}{l}\text { b Path } \\
\text { coefficient }\end{array}$} & \multicolumn{2}{|c|}{ Indirect effect } & \multirow[t]{2}{*}{ VAF } & \multirow{2}{*}{$\begin{array}{c}\text { Mediator } \\
\text { type } \\
\text { observed }\end{array}$} \\
\hline & $B$ & $t$ & $B$ & $t$ & $B$ & $t$ & $B$ & $t$ & $B$ & $t$ & & \\
\hline $\mathrm{PLC} \rightarrow \mathrm{IM} \rightarrow \mathrm{INNU}$ & 0.542 & $4.254 * * *$ & 0.207 & $2.761 * * *$ & 0.537 & $4.906 * * *$ & 0.131 & $1.702 *$ & 0.073 & $1.894 *$ & 0.261 & partial \\
\hline $\mathrm{PLC} \rightarrow \mathrm{SE} \rightarrow \mathrm{INNU}$ & 0.542 & $4.254 * * *$ & 0.207 & $2.761 * * *$ & 0.484 & $4.020 * * *$ & 0.400 & $3.372^{* * * *}$ & 0.194 & $2.623 * *$ & 0.484 & partial \\
\hline
\end{tabular}

Notes: VAF>0.80: full mediation, $0.20<\mathrm{VAF}<0.80$ : partial mediation, VAF $<0.20$ : no mediation. Significant at ${ }^{*} p<0.1,{ }^{* *} p<0.05$; ${ }^{* * *} p<0.001$

\section{DISCUSSION AND IMPLICATIONS}

\section{Theoretical Implications}

This research has several theoretical contributions.

First, this study extends the literature on IS use (Li et al., 2013; Peng et al., 2018) by identifying and highlighting psychological learning climate as a driver of innovative IS use. Specifically, this study draws on psychological climate literature and identifies psychological learning climate as one lever that comes into play in molding IS innovative use. Although research has realized the significance of innovative IS use (Li et al., 2013; Veiga et al., 2013), how to promote users' innovative use is still unknown. This research adds to recent studies which advocate to pay attention to the impact of environmental contexts on IS usage behavior (Maruping \& Magni, 2012; Liang et al., 2015).

Second, our findings unpack the impact mechanisms of psychological learning climate on innovative IS use and demonstrate that psychological learning climate has a positive impact on innovative IS use through the mediation of intrinsic motivation and creative self-efficiency. Although a few scholars have highlighted the importance of climate factors on IS innovation and exploration (Liang et al., 2015; Maruping \& Magni, 2012), the impact mechanism of psychological climate on innovative use has not been answered. Our findings provide new insights into previous studies (Maruping \& Magni, 2012; Liang et al., 2015) by examining the mediating role of intrinsic motivation and creative self-efficiency on the relationship between psychological learning climate and innovative IS use.

Third, this study identifies the differential influence of proactive motivational factors on promoting innovative IS use. The empirical results show that intrinsic motivation and creative self-efficiency have significant impacts on innovative IS use. Although these two relationships are supported as expected, this study finds that creative self-efficiency has a stronger impact on IS innovative use than intrinsic motivation, suggesting that innovative use is more likely triggered by individual creative self-efficiency. Contrary to prediction, the insignificance of the relationships between perceived usefulness and innovative use is intriguing but not surprising. One reason may be that although perceived usefulness has been considered as one important determinant for IS usage, however, its focal behaviors are on routine usage. As indicated by $\mathrm{Li}$ et al. (2013), perceived usefulness has a stronger impact effect on routine use than intrinsic motivation, but it is less influential for innovative use. Therefore, this finding is particularly worthwhile because it complements the results of recent research ( $\mathrm{Li}$ et al., 2013), showing that innovative use is more likely to be triggered by internal motivational driver.

\section{Practical Implications}

Although practitioners and scholars have realized that employees' innovative IS use is important for realizing the potential benefits of IS (Thatcher et al., 2011; Hsieh et al., 2011; Veiga et al., 2013), how to promote it is still unknown. This study could provide guidelines for managers to effectively harness perceived learning climates to promote innovative IS use.

This study shows that a learning climate is a potential lever that managers can use to promote innovative IS use in the workplace. In facilitating a psychological learning climate, team leaders should emphasize experimentation, risk-taking, and mutual sharing of lessons learned in the workplace. 
First, in 2018, most employees use IS to accomplish their daily tasks, thus managers should consider effective policies and regulations to reward employees who find novel uses for IS to more effectively accomplish tasks. Second, failure is a natural part of innovation. Thus, supervisors should pay attention to their leadership style (Shao et al., 2017), and influence their subordinates by exhibiting idealized influence and personal charisma (instead of using authoritative power) to foster a psychologically safe atmosphere in which their employees will not be afraid of negative consequences even if their risk-taking behavior ends in failure (Edmondson, 1999; Maruping \& Magni, 2012). Third, because IS innovation requires both business and technology knowledge, team leaders should encourage mutual sharing, communication, and discussion among work group members, and interaction between supervisors and subordinates (Liang et al., 2015). For instance, formal and informal meetings should be held to discuss innovative IS usage among employees, and supervisors should implement an opendoor policy to actively communicate with subordinates.

Practitioners should also be aware that employees' innovative behaviors are likely to be triggered by intrinsic motivation and creative self-efficiency. To stimulate employees' innovative ways to use IS features, managers can cultivate employees' intrinsic motivation and creative self-efficiency toward IS use by taking several actions. First, managers should provide the needed resources and supports to employees when they met with difficulties in using IS, which could enhance their intrinsic motivation and confidence to use IS in novel ways. Second, constructive feedbacks from managers on employees' innovation performance can also nature employees' intrinsic motivation. Finally, managers can focus on organizing more training programs and discussion sessions, thus to increase employees' intrinsic motivation and creative self-efficiency to engage in innovative IS use.

\section{Limitations and Future Directions}

Our study indeed has its limitations. This study only focuses on one facet-specific of psychological learning climate, and future studies could extend to other facet-specific climates, such as a climate for autonomy, which may also affect innovative IS use. In addition, future studies should give attention to the specific behaviors through which managers can shape employees' psychological learning climate. Leadership theories may provide a particular useful lens for understanding relevant behaviors.

\section{CONCLUSION}

This study develops a research model in the context of IS innovation. Using structural equation modeling, this study tests the hypotheses on the mechanisms through which psychological learning climate influences innovative IS use. The hypotheses are generally supported by the survey data. The results suggest that psychological learning climate is positively related to innovative IS use both directly and indirectly. The indirectly effect works through motivating employees' intrinsic motivation and creative self-efficiency. Counter to our expectations, this study finds that perceived usefulness does not have a significant impact on innovative IS use. The findings provide instrumental insights for managers on how to increase the beneficial innovative outcomes of implemented systems through creating a positive perceived learning climate.

\section{ACKNOWLEDGEMENT}

This research was funded by the MOE (Ministry of Education of China) Liberal arts and Social Sciences Foundation (\#19YJC630048); the grants from the National Natural Science Foundation of China (\#71701034,\#71831002,\#71672016, \#71774019,\#71601038), a grant from the Fundamental Research Funds for the Central Universities (\#20110117203), and a grant from the Program for Changjiang Scholars and Innovative Research Team in University of Ministry of Education of China (IRT_17R13). Chaoyou Wang is the corresponding author on this paper. 


\section{REFERENCES}

Ahuja, M. K., \& Thatcher, J. B. (2005). Motivating beyond intentions and toward the theory of trying: Effects of work environment and gender on post-adoption information. Management Information Systems Quarterly, 29(3), 427-459. doi:10.2307/25148691

Amabile, T. M. (1988). A model of creativity and innovation in organizations. Research in Organizational Behavior, 10(1), 123-167.

Anderson, N., Poto Nik, K., \& Zhou, J. (2014). Innovation and Creativity in Organizations: A State-of-theScience Review, Prospective Commentary, and Guiding Framework. Journal of Management, 40(5), $1297-1333$. doi:10.1177/0149206314527128

Anderson, N. R., \& West, M. A. (1998). Measuring climate for work group innovation: Development and validation of the team climate inventory. Journal of Organizational Behavior, 19(3), 235-258. doi:10.1002/ (SICI)1099-1379(199805)19:3<235::AID-JOB837>3.0.CO;2-C

Bandura, A. (1997). Self-efficacy: The exercise of self-control. New York: Freeman.

Barkhi, R., \& Kao, Y. (2011). Psychological climate and decision-making performance in a GDSS context. Information \& Management, 48(4-5), 125-134. doi:10.1016/j.im.2011.02.003

Baron, R. M., \& Kenny, D. A. (1986). The moderator-mediator variable distinction in social psychological research: conceptual, strategic, and statistical considerations. Chapman and Hall.

Bock, G., Zmud, R. W., Kim, Y., \& Lee, J. (2005). Behavioral intention formation in knowledge sharing: Examining the roles of extrinsic motivators, social-psychological forces, and organizational climate. Management Information Systems Quarterly, 29(1), 87-111. doi:10.2307/25148669

Burton-Jones, A., \& Straub, D. W. Jr. (2006). Reconceptualizing system usage: An approach and empirical test. Information Systems Research, 17(3), 228-246. doi:10.1287/isre.1060.0096

Carless, S. A. (2004). Does psychological empowerment mediate the relationship between psychological climate and job satisfaction? Journal of Business and Psychology, 18(4), 405-425. doi:10.1023/B:JOBU.0000028444.77080. c5

Chen, G., Farh, J., Campbell-Bush, E. M., Wu, Z., \& Wu, X. (2013). Teams as innovative systems: Multilevel motivational antecedents of innovation in R\&D teams. The Journal of Applied Psychology, 98(6), 1018-1027. doi:10.1037/a0032663 PMID:23565898

Chin, W. W., Marcolin, B. L., \& Newsted, P. R. (2003). A partial least squares latent variable modeling approach for measuring interaction effects: Results from a Monte Carlo simulation study and an electronic-mail emotion/ adoption study. Information Systems Research, 14(2), 189-217. doi:10.1287/isre.14.2.189.16018

Davis, F. D. (1989). Perceived usefulness, perceived ease of use, and user acceptance of information technology. Management Information Systems Quarterly, 13(3), 319-340. doi:10.2307/249008

Davis, F. D., Bagozzi, R. P., \& Warshaw, P. R. (1992). Extrinsic and intrinsic motivation to use computers in the workplace1. Journal of Applied Social Psychology, 22(14), 1111-1132. doi:10.1111/j.1559-1816.1992.tb00945.x

Deci, E. L., \& Ryan, R. M. (2000). The "what" and "why" of goal pursuits: Human needs and the selfdetermination of behavior. Psychological Inquiry, 11(4), 227-268. doi:10.1207/S15327965PLI1104_01

Diamantopoulos, A., \& Siguaw, J. A. (2006). Formative versus reflective indicators in organizational measure development: A comparison and empirical illustration. British Journal of Management, 17(4), $263-282$. doi:10.1111/j.1467-8551.2006.00500.x

Durcikova, A., \& Fadel, K. J. (2016). Knowledge sourcing from repositories: The role of system characteristics and psychological climate. Information \& Management, 53(1), 64-78. doi:10.1016/j.im.2015.08.005

Durcikova, A., Fadel, K. J., Butler, B. S., \& Galletta, D. F. (2011). Research note- knowledge exploration and exploitation: The impacts of psychological climate and knowledge management system access. Information Systems Research, 22(4), 855-866. doi:10.1287/isre.1100.0286 
Edmondson, A. (1999). Psychological safety and learning behavior in work teams. Administrative Science Quarterly, 44(2), 350-383. doi:10.2307/2666999

Gefen, D., Straub, D., \& Boudreau, M. (2000). Structural equation modeling and regression: Guidelines for research practice. Communications of the Association for Information Systems, 4(1), 7.

Glomb, T. M., \& Liao, H. (2003). Interpersonal aggression in work groups: Social influence, reciprocal, and individual effects. Academy of Management Journal, 46(4), 486-496.

Griffin, M. A., Neal, A., \& Parker, S. K. (2007). A new model of work role performance: Positive behavior in uncertain and interdependent contexts. Academy of Management Journal, 50(2), 327-347. doi:10.5465/ amj.2007.24634438

Hsieh, J. P., Rai, A., \& Xu, S. X. (2011). Extracting business value from IT: A sensemaking perspective of postadoptive use. Management Science, 57(11), 2018-2039. doi:10.1287/mnsc.1110.1398

Hsieh, J. P., \& Wang, W. (2007). Explaining employees' extended use of complex information systems. European Journal of Information Systems, 16(3), 216-227. doi:10.1057/palgrave.ejis.3000663

Hu, Q., Dinev, T., Hart, P., \& Cooke, D. (2012). Managing employee compliance with information security policies: The critical role of top management and organizational culture. Decision Sciences, 43(4), 615-660. doi:10.1111/j.1540-5915.2012.00361.x

Huang, M., Bhattacherjee, A., \& Wong, C. (2017). Gatekeepers' innovative use of IT: An absorptive capacity model at the unit level. Information \& Management, 55(2), 235-244. doi:10.1016/j.im.2017.06.001

Hulland, J. (1999). Use of partial least squares (PLS) in strategic management research: A review of four recent studies. Strategic Management Journal, 20(2), 195-204. doi:10.1002/(SICI)1097-0266(199902)20:2<195::AIDSMJ13>3.0.CO;2-7

Igbaria, M., \& Iivari, J. (1995). The effects of self-efficacy on computer usage. Omega, 23(6), 587-605. doi:10.1016/0305-0483(95)00035-6

Jasperson, J. S., Carter, P. E., \& Zmud, R. W. (2005). A comprehensive conceptualization of post-adoptive behaviors associated with information technology enabled work systems. Management Information Systems Quarterly, 29(3), 525-557. doi:10.2307/25148694

Ke, W., Tan, C., Sia, C., \& Wei, K. (2012). Inducing intrinsic motivation to explore the enterprise system: The supremacy of organizational levers. Journal of Management Information Systems, 29(3), 257-290. doi:10.2753/ MIS0742-1222290308

Kettinger, W. J., Li, Y., Davis, J. M., \& Kettinger, L. (2015). The roles of psychological climate, information management capabilities, and IT support on knowledge-sharing: An MOA perspective. European Journal of Information Systems, 24(1), 59-75. doi:10.1057/ejis.2013.25

Ko, D., Kirsch, L. J., \& King, W. R. (2005). Antecedents of knowledge transfer from consultants to clients in enterprise system implementations. Management Information Systems Quarterly, 29(1), 59-85. doi: $10.2307 / 25148668$

Koys, D. J., \& DeCotiis, T. A. (1991). Inductive measures of psychological climate. Human Relations, 44(3), 265-285. doi:10.1177/001872679104400304

Lee, M. K., Cheung, C. M., \& Chen, Z. (2005). Acceptance of Internet-based learning medium: The role of extrinsic and intrinsic motivation. Information \& Management, 42(8), 1095-1104. doi:10.1016/j.im.2003.10.007

Li, X., Hsieh, J. J. P., \& Rai, A. (2013). Motivational differences across post-Acceptance information system usage behaviors: An investigation in the business intelligence systems context. Information Systems Research, 24(3), 659-682. doi:10.1287/isre.1120.0456

Liang, H., Peng, Z., Xue, Y., Guo, X., \& Wang, N. (2015). Employees' exploration of complex systems: An integrative view. Journal of Management Information Systems, 32(1), 322-357. doi:10.1080/07421222.2015. 1029402 
Liang, H., Saraf, N., Hu, Q., \& Xue, Y. (2007). Assimilation of enterprise systems: The effect of institutional pressures and the mediating role of top management. Management Information Systems Quarterly, 30(1), 59-87. doi: $10.2307 / 25148781$

Liang, H., Xue, Y., Ke, W., \& Wei, K. K. (2010). Understanding the Influence of Team Climate on IT Use. Journal of the Association for Information Systems, 11(8), 414-432. doi:10.17705/1jais.00235

Liu, L., Feng, Y., Hu, Q., \& Huang, X. (2011). From transactional user to VIP: How organizational and cognitive factors affect ERP assimilation at individual level. European Journal of Information Systems, 20(2), 186-200. doi:10.1057/ejis.2010.66

MacKinnon, D. W. (1962). The nature and nurture of creative talent. The American Psychologist, 17(7), 484-495. doi:10.1037/h0046541

Maruping, L. M., \& Magni, M. (2012). What's the Weather Like? The Effect of Team Learning Climate, Empowerment Climate, and Gender on Individuals' Technology Exploration and Use. Journal of Management Information Systems, 29(1), 79-114. doi:10.2753/MIS0742-1222290103

Maruping, L. M., \& Magni, M. (2015). Motivating employees to explore collaboration technology in team contexts. Management Information Systems Quarterly, 39(1), 1-16. doi:10.25300/MISQ/2015/39.1.01

Mills, A., \& Chin, W. (2007). Conceptualizing creative use: an examination of the construct and its determinants. Paper presented at the Americas Conference on Information Systems (AMCIS).

Morris, M. G., \& Venkatesh, V. (2010). Job characteristics and job satisfaction: Understanding the role of enterprise resource planning system implementation. Management Information Systems Quarterly, 34(1), 143-161. doi:10.2307/20721418

Orlikowski, W. J., \& Scott, S. V. (2008). 10 sociomateriality: Challenging the separation of technology, work and organization. The Academy of Management Annals, 2(1), 433-474. doi:10.1080/19416520802211644

Parker, S. (2000). From passive to proactive motivation: The importance of flexible role orientations and role breadth self-efficacy. Applied Psychology, 49(3), 447-469. doi:10.1111/1464-0597.00025

Parker, S. K., Bindl, U. K., \& Strauss, K. (2010). Making things happen: A model of proactive Motivation., 36(4), 827-856.

Parker, S. K., \& Collins, C. G. (2010). Taking stock: Integrating and differentiating multiple proactive behaviors. Journal of Management, 36(3), 633-662. doi:10.1177/0149206308321554

Peng, Z., Sun, Y., \& Guo, X. (2018). Antecedents of employees' extended use of enterprise systems: An integrative view of person, environment, and technology. International Journal of Information Management, 39, $104-120$. doi:10.1016/j.ijinfomgt.2017.11.007

Podsakoff, P. M., MacKenzie, S. B., Lee, J., \& Podsakoff, N. P. (2003). Common method biases in behavioral research: A critical review of the literature and recommended remedies. The Journal of Applied Psychology, 88(5), 879-903. doi:10.1037/0021-9010.88.5.879 PMID:14516251

Preacher, K. J., \& Hayes, A. F. (2004). SPSS and SAS procedures for estimating indirect effects in simple mediation models. Behavior Research Methods, Instruments, \& Computers, 36(4), 717-731. doi:10.3758/ BF03206553 PMID:15641418

Rezvani, A., Dong, L., \& Khosravi, P. (2017). Promoting the continuing usage of strategic information systems: The role of supervisory leadership in the successful implementation of enterprise systems. International Journal of Information Management, 37(5), 417-430. doi:10.1016/j.ijinfomgt.2017.04.008

Ryan, R. M., \& Deci, E. L. (2000). Intrinsic and extrinsic motivations: Classic definitions and new directions. Contemporary Educational Psychology, 25(1), 54-67. doi:10.1006/ceps.1999.1020 PMID:10620381

Schmitz, K., Teng, J. T., \& Webb, K. (2016). Capturing the Complexity of Malleable IT Use: Adaptive Structuration Theory for Individuals. Management Information Systems Quarterly, 40(3), 663-686. doi:10.25300/ MISQ/2016/40.3.07

Scott, S. G., \& Bruce, R. A. (1994). Determinants of innovative behavior: A path model of individual innovation in the workplace. Academy of Management Journal, 37(3), 580-607. 
Shao, Z., Feng, Y., \& Wang, T. (2017). Charismatic leadership and tacit knowledge sharing in the context of enterprise systems learning: The mediating effect of psychological safety climate and intrinsic motivation. Behaviour \& Information Technology, 36(2), 194-208. doi:10.1080/0144929X.2016.1221461

Sobel, M. E. (1982). Asymptotic Confidence Intervals for Indirect Effects in Structural Equation Models. Sociological Methodology, 13(13), 290-312. doi:10.2307/270723

Straub, D., Boudreau, M., \& Gefen, D. (2004). Validation guidelines for IS positivist research. Communications of the Association for Information Systems, 13(1), 380-427.

Thatcher, J. B., McKnight, D. H., Baker, E. W., Arsal, R. E., \& Roberts, N. H. (2011). The role of trust in postadoption IT exploration: An empirical examination of knowledge management systems. IEEE Transactions on Engineering Management, 58(1), 56-70. doi:10.1109/TEM.2009.2028320

Tierney, P., \& Farmer, S. M. (2002). Creative self-efficacy: Its potential antecedents and relationship to creative performance. Academy of Management Journal, 45(6), 1137-1148.

Vallerand, R. J. (1997). Toward A hierarchical model of intrinsic and extrinsic motivation. Advances in Experimental Social Psychology, 29(08), 271-360. doi:10.1016/S0065-2601(08)60019-2

Veiga, J. F., Keupp, M. M., Floyd, S. W., \& Kellermanns, F. W. (2013). The longitudinal impact of enterprise system users' pre-adoption expectations and organizational support on post-adoption proficient usage. European Journal of Information Systems, 23(6), 691-707. doi:10.1057/ejis.2013.15

Wang, C., Zuo, M., \& An, X. (2017). Differential influences of perceived organizational factors on younger employees' participation in offline and online intergenerational knowledge transfer. International Journal of Information Management, 37(6), 650-663. doi:10.1016/j.jinfomgt.2017.06.003

Wang, W., Hsieh, J. J. P., Butler, J. E., \& Hsu, S. (2008). Innovate with complex information technologies: A theoretical model and empirical examination. Journal of Computer Information Systems, 49(1), 27-36. doi:10 $.1080 / 08874417.2008 .11645303$

Wang, W., Liu, L., Feng, Y., \& Wang, T. (2014). Innovation with IS usage: Individual absorptive capacity as a mediator. Industrial Management \& Data Systems, 114(8), 1110-1130. doi:10.1108/IMDS-05-2014-0160

Worren, N., Moore, K., \& Cardona, P. (2002). Modularity, strategic flexibility, and firm performance: A study of the home appliance industry. Strategic Management Journal, 23(12), 1123-1140. doi:10.1002/smj.276

Xue, Y., Bradley, J., \& Liang, H. (2011). Team climate, empowering leadership, and knowledge sharing. Journal of Knowledge Management, 15(2), 299-312. doi:10.1108/13673271111119709

Zhou, Z., Fang, Y., Vogel, D. R., Jin, X., \& Zhang, X. (2012). Attracted to or Locked In? Predicting Continuance Intention in Social Virtual World Services. Journal of Management Information Systems, 29(1), 273-306. doi:10.2753/MIS0742-1222290108 


\section{APPENDIX}

Table 9. Survey Instrument

\begin{tabular}{|c|c|}
\hline Questionnaire Items & $\begin{array}{l}\text { Primary Source of the } \\
\text { Measurement }\end{array}$ \\
\hline Psychological learning climate & \multirow[t]{4}{*}{ Maruping \& Magni (2012) } \\
\hline In my team, we are encouraged to take risks when trying new ideas & \\
\hline In my team, there is freedom to experiment & \\
\hline In my team, errors are considered a source of learning & \\
\hline Intrinsic motivation & \multirow[t]{4}{*}{ Ko et al. (2005) } \\
\hline I enjoy learning business and technical knowledge about ERP systems & \\
\hline $\begin{array}{l}\text { I have to feel that I am personally benefitting from learning business and technical } \\
\text { knowledge about the ERP systems }\end{array}$ & \\
\hline $\begin{array}{l}\text { I enjoy learning business and technical knowledge about ERP systems that are } \\
\text { completely new to me }\end{array}$ & \\
\hline Perceived usefulness & \multirow[t]{3}{*}{ Davis (1989) } \\
\hline I believe that ERP systems can improve my job performance & \\
\hline I believe that ERP systems can enhance my effectiveness in my job & \\
\hline Creative self-efficiency & \multirow{4}{*}{$\begin{array}{l}\text { Tierney \& Farmer (2000) } \\
\text { Carmeli \& Schaubroeck } \\
(2007)\end{array}$} \\
\hline I have confidence in my ability to use ERP systems innovatively & \\
\hline I am confident that I can use ERP systems in novel ways & \\
\hline I am confident that I can perform creatively on many different tasks using ERP systems & \\
\hline Innovation use & \multirow[t]{4}{*}{ Li et al. (2013) } \\
\hline I have used ERP systems in novel ways to support my work & \\
\hline I have developed new applications based on ERP systems to support my work & \\
\hline I have discovered new uses of ERP systems to enhance my work performance & \\
\hline
\end{tabular}

Yuanyuan Guo is an assistant professor in the Collaborative Innovation Center for Transport Studies in the School of Maritime Economics and Management at Dalian Maritime University, China. Her research areas include enterprise information systems implementation and assimilation, information system (IS) innovation, organizational culture and climate. Her work has been published in Behaviour \& Information Technology, Asia Pacific Journal of Tourism Research, Journal of Travel \& Tourism Marketing and the Hawaii International Conference on System Sciences (HICSS).

Chaoyou Wang is an assistant professor in the School of Management Science and Engineering at Dongbei University of Finance and Economics, China. His research areas include information systems innovation and information systems assimilation. His work has been published in Behaviour \& Information Technology, Applied Economic Letters and the Hawaii International Conference on System Sciences (HICSS). 